\title{
CARACTERIZACIÓN DE LAS REGIONES ORGANIZADORAS NUCLEOLARES EN LAS CÉLULAS DEL TUMOR VENÉREO TRANSMISIBLE EN CANINOS: ESTUDIO HISTOQUÍMICO
}

\author{
Characterization of Nucleolar Organizer Regions in Cells of \\ Transmissible Venereal Tumor in Canine: Histochemical Study \\ Luis Rodríguez I. ${ }^{1}$, Rosa Perales C. ${ }^{1,2}$, Alfonso Chavera C. ${ }^{1}$, César Gavidia Ch. ${ }^{3}$, \\ Diego Díaz C. ${ }^{4}$
}

\section{RESUMEN}

\begin{abstract}
El objetivo del presente estudio fue visualizar y caracterizar las Regiones Organizadoras Nucleolares Argénticas (AgNORs) en células neoplásicas del tumor venéreo transmisible (TVT) de caninos a través de la impregnación con nitrato de plata. Se trabajó con una muestra tomada al azar de tejido parafinado de 30 caninos diagnosticados histológicamente (con coloración de Hematoxilina y Eosina) como TVT canino entre el 2000 al 2006. En 100 células por muestra se visualizó la presencia y ubicación de los AgNORs en las células neoplásicas. Se encontró un número medio de AgNORs por célula de 1.53, por núcleo de 0.91 y por nucléolo de 0.62. La distribución de los AgNORs en el total de células evaluadas fue de 60.7\% (1821/3000) en el núcleo, 34.3\% (1029/3000) en el nucléolo y 5\% (150/3000) en ambas estructuras.
\end{abstract}

Palabras clave: regiones organizadoras nucleares, tumor venéreo transmisible, marcador tumoral, neoplasia

\section{Abstract}

The objective of the present study was to visualize and characterize the Nucleolar Organizer Regions (AgNORs) in Cells of Transmissible Venereal Tumor (TVT) in the canine through the impregnation with silver nitrate. One sample was collected at random from paraffin tissue of 30 canine tissue samples that were histological diagnosed (using Hematoxylin and Eosin stain) as TVT during the period of 2000-2006. The AgNORs were visualized and localized in 100 cells per sample. The average number of AgNORs per cell was 1.53, per cell nucleus was 90.91 and per nucleolus was 0.62 . The distribution of AgNORs in the total number of cells was 60.7\% (1821/3000) in the nucleus, 34.3\% (1029/ $3000)$ in the nucleolus, and 5\% (150/3000) in both structures.

Key words: nuclear organizer regions, canine transmissible venereal tumor, tumorlike marker, neoplasia

\footnotetext{
${ }^{1}$ Laboratorio de Histología, Embriología y Patología Veterinaria, ${ }^{3}$ Laboratorio de Medicina Veterinaria Preventiva, ${ }^{4}$ Laboratorio de Farmacología y Toxicología Veterinaria, Facultad de Medicina Veterinaria, Universidad Nacional Mayor de San Marcos, Lima

${ }^{2}$ E-mail: rperales_fmv@hotmail.com
} 


\section{INTRODUCCIÓN}

El diagnóstico de neoplasias se realiza mediante la histopatología, prueba diagnóstica que identifica el tipo y el grado de malignidad; pero se requiere de técnicas adicionales que midan parámetros biológicos que apoyen en la evaluación del tratamiento y en determinar la probabilidad de vida del paciente (López Muñiz et al., 2001). Entre estas, se halla la técnica histoquímica de coloración de las Regiones Organizadoras Nucleolares (NORs) utilizando la impregnación con nitrato de plata, por la cual se le denomina Regiones Organizadoras Nucleolares Argirofílicas (AgNORs). Los NORs son segmentos de ADN que codifican el ARN ribosómico para la síntesis de proteínas, las cuales se ubican en las bandas cortas de los cromosomas acrocéntricos 13, 14, 15, 21 y 22 de las células eucarióticas humanas (Derenzini, 2000; López-Muñiz et al., 2001; Yasdi y Taghavi, 2005). Asociado a estos NORs existen un conjunto de nucleoproteínas de tipo acídicas no histónicas, que mediante técnicas electroforéticas fueron identificadas durante la interfase del ciclo celular. La nucleolina, fosfoproteína de $105 \mathrm{kDa}$ que interviene en la transcripción de las moléculas de ARNr, y la nucleofosmina o proteína B23, fosfoproteína de 38-39 kDa, involucrada en las fases finales de la organización de la partícula pre-ribosomal (Derenzini, 2000; Sirri et al., 2000; Giraldo et al., 2003b).

Diversos estudios indican un incremento en número de los AgNORs en células malignas comparadas con células benignas o células normales (Giuffrè et al., 1998; Trerè, 2000). Existe una relación con la actividad transcripcional, la diferenciación celular y la actividad proliferativa tumoral, reflejando de esa forma el estadio de activación y el grado de transformación maligna de ciertos tejidos (Sirri et al., 2000; Trerè, 2000).

La mayor presencia de AgNORs en las células neoplásicas del cáncer de próstata humano fue demostrada por Plotón et al. (1986). Actualmente se cuenta con un protocolo estandarizado de impregnación del nitrato de plata (Öfner y Schmid, 1996). El número, área ocupada y distribución de las NORs depende de la actividad trascripcional del RNA y del estadio celular, por lo que la evaluación de estos parámetros permite obtener información sobre su función (Warnakulasuriya y Jonson, 1993).

El uso de esta técnica, empleada en patología humana desde hace varias décadas (Akhtar et al., 2004), ha despertado un reciente interés en patología veterinaria debido a la simplicidad y bajo costo. Se ha reportado un número de AgNORs medio por célula de 4.46 en el adenocarcinoma, 3.98 en el tumor mamario mixto maligno y 3.68 en el tumor mamario mixto benigno (Giraldo et al., 2003b). Los parámetros de cuantificación de los AgNORs (número, tamaño y distribución) pueden ayudar a discriminar entre neoplasias benignas y malignas, tanto en muestras citológicas como histológicas, por lo que este método puede ser un auxiliar como marcador cuantitativo en alteraciones celulares incipientes, antes que los cambios morfológicos puedan ser detectados histológicamente (Warnakulasuriya y Jonson , 1993; Öfner y Schmid, 1996).

El tumor venéreo transmisible canino (TVT canino) es una neoplasia común en los caninos. Se caracteriza por presentar células neoplásicas viables que son transmitidas a un huésped susceptible a través del coito, contacto o por inoculación experimental (Scott et al., 2002). Se ha reportado casos de pacientes que no ceden al tratamiento convencional para esta neoplasia (R. Perales, Lima, comunicación personal), por lo que se hace necesario evaluar la respuesta del tejido neoplásico a la quimioterapia.

El objetivo del presente estudio fue visualizar los AgNORs en la célula neoplásica del TVT canino utilizando la tinción de nitrato de plata en tejidos incluidos en parafina. 


\section{MATERIALES Y MéTODOS}

Se trabajó con muestras de tejido parafinado de 30 caninos de varias edades, razas y sexos, afectados con el Tumor Venéreo Transmisible (TVT), tanto en la zona genital como extragenital. Las muestras se diagnosticaron microscópicamente utilizando la coloración de Hematoxilina y Eosina (HE) en el Laboratorio de Histología, Embriología y Patología Veterinaria de la Facultad de Medicina Veterinaria de la Universidad Nacional Mayor de San Marcos, entre los años 2000 al 2006.

El tamaño muestral $(\mathrm{n}=30)$ se calculó de acuerdo al Teorema del Límite Central de la Teoría Avanzada de Probabilidades (Spiegel, 1991). De cada tejido parafinado se tomó una muestra al azar y se sometió a la técnica histoquímica de coloración de las Regiones Organizadoras Nucleolares (NORs) a través de la impregnación con nitrato de plata, siguiendo el protocolo establecido por el "Comité Internacional sobre Cuantificación de los AgNORs” (Trerè, 2000).

Los NORs se visualizan al microscopio óptico (100x y aceite de inmersión) como puntos redondos o elongados negros bien definidos, dentro del núcleo o nucleólo en células normales y neoplásicas (Plotón et al., 1986; Sirri et al., 2000; Giraldo et al., 2003a). La cuantificación de los AgNORs en las células atípicas del TVT canino se realizó evaluando 20 células elegidas al azar en cinco campos por muestra, de modo de observar 100 células por animal.

La cuantificación de los AgNORs en las células neoplásicas se hizo con base al número de AgNORs por célula, por núcleo celular y por nucléolo celular. Asimismo, su distribución en las células neoplásicas se determinó con relación a su presencia en el núcleo, en el nucléolo y en ambas estructuras.

Los resultados se sometieron a un análisis de tipo descriptivo, donde se utilizó la me- dia como medida de tendencia central y la desviación estándar como medida de dispersión. Los resultados de los parámetros de distribución se llevaron a una valoración porcentual.

\section{Resultados}

La coloración de HE permitió visualizar las características celulares atípicas en los 30 casos de TVT en caninos. Los AgNORs se observaron, con la coloración de nitrato de plata, en el interior de las células como puntos redondos o elongados teñidos de negro ubicados en el núcleo o en el nucléolo, y en algunas células en ambas estructuras, mientras que el resto de la célula se tiñó de color amarillo pardo (Figs. 1 y 2).

La media de AgNORs por célula fue de $1.53 \pm 0.87$, mientras que la media de AgNORs en el núcleo de la célula fue de $0.91 \pm 0.85$ y en el nucléolo de $0.62 \pm 0.87$. Asimismo, el porcentaje de ubicación de los AgNORs del total de células evaluadas con TVT canino fue de $60.7 \%$ (1821/3000) en el núcleo (Fig. 1), 34.3\% (1029/3000) en el nucléolo (Fig. 2) y 5\% (150/3000) en ambas estructuras (Fig. 2).

No se encontró una relación estadística entre el sexo del animal o la procedencia de la neoplasia (genital o extragenital) con la ubicación de los AgNOR en el núcleo o en el nucléolo. El reducido número de casos por grupo etáreo y raza no permitió evaluar su relación con el número de AgNORs en las células neoplásicas del TVT canino.

\section{Discusión}

Las muestras archivadas desde el año 2000 no presentaron problema con la coloración argéntica ni con la coloración de hematoxilina y eosina; confirmando la viabilidad de la tinción del nitrato de plata sobre tejidos parafinados archivados (Linder, 1993; 


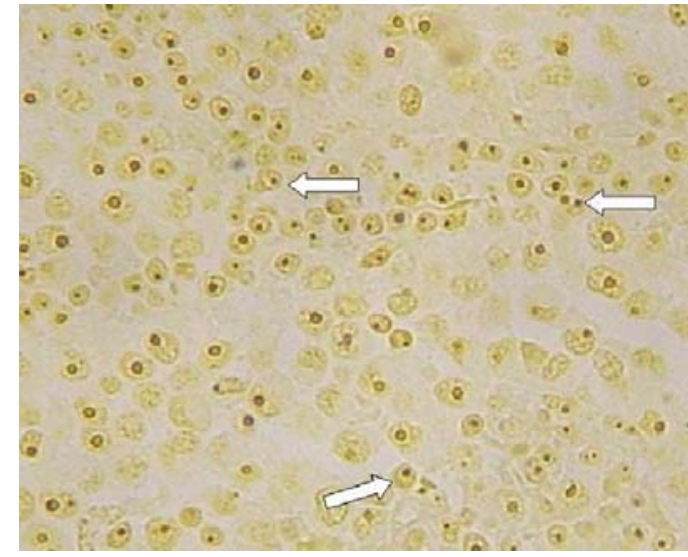

A

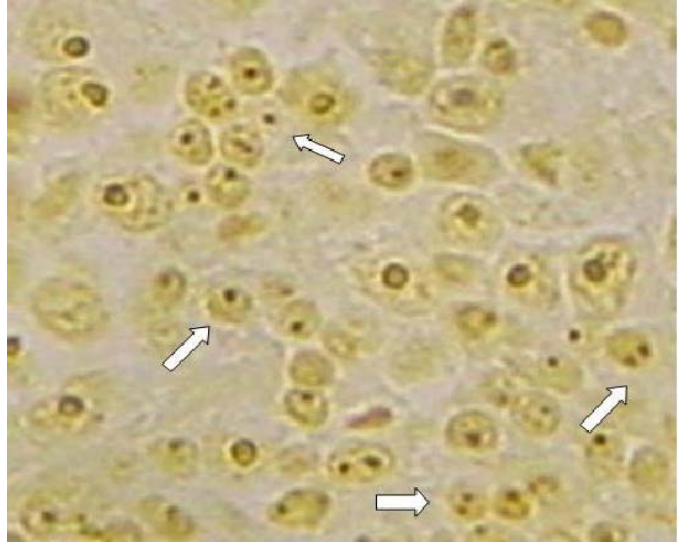

B

Figura 1. Histología de los AgNORs en el núcleo celular del Tumor Venéreo Transmisible canino. A: 40x; B: 100x

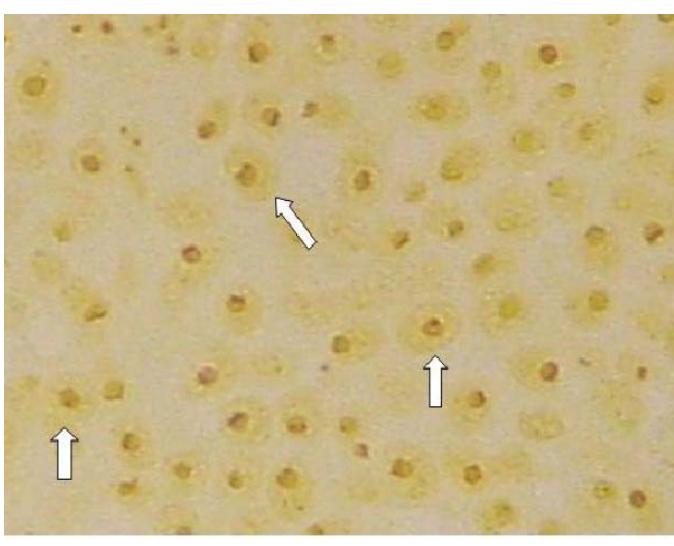

A

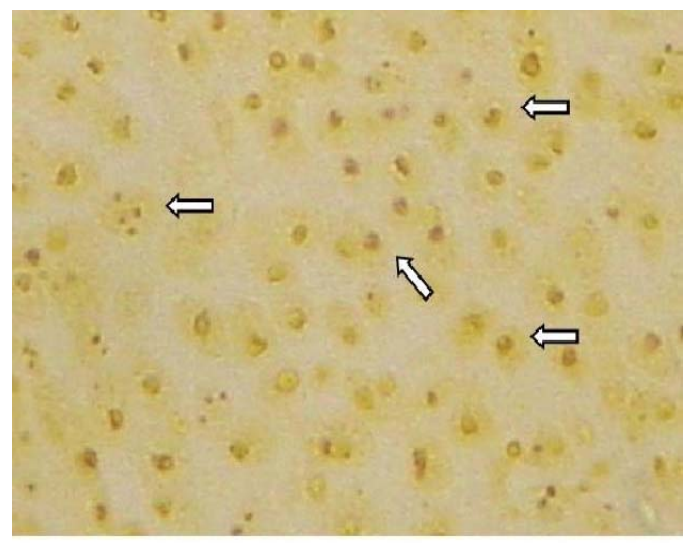

B

Figura 2. Histología de los AgNORs en el nucléolo celular (A) (100x) y en el núcleo y nucléolo celular (B) del Tumor Venéreo Transmisible canino (100x)

Giraldo et al., 2003); sin embargo, durante la cuantificación de AgNOR por célula se visualizó, en un mínimo grupo, imágenes de algunos agregados inespecíficos como puntos pequeños dispersos en la zona nuclear que no presentaban las características propias del AgNOR, debido al fijador empleado, formol bufferado al 10\% (Trerè, 2000).

La distribución de 60.7\% de AgNORs en el núcleo de la célula neoplásica del TVT canino confirma la relación entre el grado de malignidad y el grado de dispersión de los AgNORs en la célula, donde la ubicación de los AgNORs en el núcleo es común en células altamente malignas (Giraldo et al., 2003). También se confirma que el TVT canino es histológicamente una neoplasia maligna (Moulton, 1978).

El 1.53 de AgNORs por célula neoplásica del TVT canino podría ser considerado como de una malignidad de bajo grado, si se considera los resultados de estudios 
en otras neoplasias como los linfomas de Hodgkin's, donde se encontró una media de AgNORs de 1.66 y de 5.19 para neoplasias de bajo y alto grado, respectivamente (Yasdi y Taghavi, 2005). Esto es importante cuando se pretenda hacer un seguimiento del tratamiento en el TVT canino.

El número de AgNORs por núcleo (0.91 \pm 0.85 ) encontrado en el presente estudio coincide con el valor de 1.6 reportado por Harmelin et al. (1995) en un grupo de animales tratados con vincristina. En ese estudio, en el caso de animales con metástasis agresiva se encontró 2.2 AgNORs por núcleo celular, indicando que el número se incrementa con el nivel de malignidad.

Arora et al. (1996) indican que la tinción AgNOR puede ser usada como método para estimar la proliferación celular de una neoplasia, pudiendo diferenciar el tejido normal del crecimiento proliferativo no neoplásico, neoplásico benigno y neoplásico maligno en tejidos blandos; por lo tanto, se debería evaluar la presencia de AgNORs en histiocitos ya que de acuerdo con estudios inmunohistoquímicos existen reportes que avalan el origen histiocitario del TVT canino (Scott et al., 2002). La caracterización en base a parámetros de ubicación y cuantificación de los AgNORs en la célula del TVT canino puede establecer pautas para que, en estudios posteriores, se pueda evaluar el pronóstico y evolución del TVT canino, como se realiza en otras neoplasias (Orellana et al., 2004).

Los resultados de la técnica de impregnación de nitrato de plata se afectan por factores tales como fijador, temperatura y duración de la reacción de la tinción, y pueden variar para cada neoplasia (Derenzini, 2000; Trerè, 2000). Sin embargo, con el adecuado control y estandarización, la técnica AgNOR es un parámetro accesible, reproducible, económico y comparable que se puede utilizar en forma rutinaria de manera paralela a la técnica histopatológica.

\section{Conclusiones}

- A través de la técnica de impregnación de nitrato de plata en la coloración de las Regiones Organizadoras Nucleolares Argénticas (AgNORs), se comprobó su presencia en las células neoplásicas del Tumor Venéreo Transmisible canino.

- Los AgNORs en las células del TVT canino se presentaron mayormente en el núcleo (60.7\%) y, en menor grado, en el nucléolo o en ambas estructuras.

- El número medio de AgNORs por célula fue de 1.53.

\section{Literatura Citada}

1. Akhtar GN, Chaudrhy NA, Tayyab M, Khan SA. 2004. AgNOR staining in malignant and benign effusions. Pak J Med Sci 20(1): 29-32.

2. Arora HL, Arora N, Solanki RL. 1996. Argyrophilic nucleolar organizer regions in soft tissue tumors. Indian J Pathol Microbiol 39: 257-263.

3. Derenzini M. 2000. The AgNORs. Micron 31: 117-120.

4. Giraldo GE, Aranzazu DA, Rodríguez B, Pérez MM, Ramírez MC. 2003a. Caracterización de las regiones organizadoras nucleolares coloreadas con plata (AgNORs) en tumores cutáneos caninos. Rev Col Cienc Pec 16(2): 132-138.

5. Giraldo GE, Aranzazu DA, Rodríguez B, Pérez MM, Ramírez MC. $2003 b$. Caracterización de las regiones organizadoras nucleolares coloreadas con plata (AgNORs) en tumores mamarios caninos. Rev Col Cienc Pec 16(1): 33-39.

6. Giuffrè G Caruso R, Barresi G, Tuccari G. 1998. Prognostic significance of standardized AgNOR analysis in early and advanced gastric carcinomas. Virchows Arch 433: 261-266.

7. Harmelin A, Zuckerman A, Nyska A. 1995. Correlation of AgNOR protein 
measurements with prognosis in canine Transmissible Venereal Tumor. J Comp Path 112: 429-433.

8. Linder LE. 1993. Improvements in the silver - Staining Technique for Nuclear Organizer Regions (AgNOR). J Histochem Cytochem 41: 439-445.

9. López-Muñiz A, Treviño A, Hernández L, Herrero A. 2001. Valoración de las regiones organizadoras nucleares en lesiones melánicas benignas y malignas de piel. Rev Cubana Med 40(1): 17-23.

10. Moulton JE. 1978. Tumors in domestic animals. $2^{\text {nd }}$ ed. Berkeley, USA: University of California. $465 \mathrm{p}$.

11. Öfner D, Schmid KW. 1996. Standarized AgNOR analysis: its usefulness in surgical oncology. Histochem Cell Biol 106: 193-196.

12. Jaimes-Freyre N, Ortega A. 2004. Evaluación del grado de queratinización y el recuento de AgNORs en citología exfoliativa de mucosa oral de individuos fumadores y no fumadores. Med Oral 9: 197-203.
13. Plotón D, Menager M, Jeannesson P, Himber G Pigeon F, Adnet J. 1986. Improvement in the staining and in the visualization of the argyrophilic proteins of the nucleolar organizer regions at the optical level. Histochemical J 18: 5-14.

14. Scott D, Miller W, Griffin C. 2002. Dermatología en pequeños animales. $6^{\mathrm{a}}$ ed. Buenos Aires: Ed. Intermédica. 1572 p.

15. Sirri V, Roussel P, Hernández-Verdum D. 2000. The AgNOR proteins: qualitative and quantitative changes during the cell cycle. Micron 31: 121-126.

16. Spiegel MR. 1991. Estadística. $2^{\mathrm{a}}$ ed. EEUU: McGraw-Hill Interamericana. $432 \mathrm{p}$.

17. Trerè D. 2000. AgNOR staining and quantification. Micron 31: 127-131.

18. Warnakulasuriya K, Jonson N. 1993. Nucleolar organizer region (NOR) distribution as a diagnostic marker in oral keratosis, dysplasia and squamous cell carcinoma. J Oral Pathol Med 22: 77-81.

19. Yasdi I, Taghavi N. 2005. The assessment of AgNORs in grading of head and neck non-Hodgkin's lymphoma. Arch Iranian Med 4: 282-285. 